\title{
Synthesis of optically active through-space conjugated polymers consisting of planar chiral [2.2] paracyclophane and quaterthiophene
}

\author{
Yasuhiro Morisaki, Kenichi Inoshita, Shotaro Shibata and Yoshiki Chujo \\ Polymer Journal (2015) 47, 278-281; doi:10.1038/pj.2014.118; published online 10 December 2014
}

\section{INTRODUCTION}

Some [2.2] paracyclophane compounds ${ }^{1,2}$ exhibit planar chirality, a unique feature derived from suppressed rotary motion in the two fixed phenylene units. ${ }^{2-4}$ Various [2.2]paracyclophanes have been optically resolved, ${ }^{3-7}$ and optically active [2.2] paracyclophane compounds have been used mainly as chiral auxiliaries in the fields of organic and organometallic chemistry. Recently, we studied planar chiral [2.2] paracyclophanes and developed a novel approach to obtain enantiopure 4,12-disubstituted ${ }^{6}$ and 4,7,12,15-tetrasubstituted [2.2] paracyclophanes. ${ }^{8}$ These molecules were employed as chiral building blocks to construct optically active through-space-conjugated systems in an effort to apply planar chirality in the fields of polymer and materials chemistry. Here, we report the synthesis of optically active through-space-conjugated copolymers consisting of enantiopure 4,12disubstituted [2.2]paracyclophane and quaterthiophene to expand the substrate scope. In a single polymer chain, $2,2^{\prime \prime \prime}$-dixylyl-2,2': $: 5^{\prime}, 2^{\prime \prime}: 5^{\prime}$ $', 2^{\prime \prime \prime}$-quaterthiophenes are stacked by the [2.2]paracyclophane skeleton. ${ }^{9,10}$ In addition to the previously reported optical resolutions by the diastereomer method, ${ }^{6}$ chromatographic optical resolutions of key compounds with chiral columns were successfully carried out. The obtained polymers exhibited beneficial chiroptical properties such as circularly polarized luminescence (CPL) with a relatively large CPL dissymmetry factor $\left(g_{\text {lum }}\right)$. We disclose herein that the optically active through-space- conjugated polyarylenes, instead of poly( $p$-aryleneethynylene)s, emit clear CPL due to the planar chiral [2.2] paracyclophane.

\section{EXPERIMENTAL PROCEDURE}

Synthesis of polymer $\left(R_{\mathrm{p}}\right)-\mathrm{P} 1$

The mixture of $\mathrm{Pd}_{2}(\mathrm{dba})_{3}(3.7 \mathrm{mg}, 0.004 \mathrm{mmol}), \mathrm{P}(t-\mathrm{Bu})_{3} \cdot \mathrm{HBF}_{4}(5.8 \mathrm{mg}, 0.020$ $\mathrm{mmol}), \mathrm{K}_{3} \mathrm{PO}_{4}(42.5 \mathrm{mg}, 0.200 \mathrm{mmol})$, compound $\left(R_{\mathrm{p}}\right)-4(10.6 \mathrm{mg}, 0.020$ $\mathrm{mmol})$, and compound $5(15.1 \mathrm{mg}, 0.020 \mathrm{mmol})$ was dissolved in tetrahydrofuran $(1.0 \mathrm{ml})$ and $\mathrm{H}_{2} \mathrm{O}(1.0 \mathrm{ml})$ at room temperature under $\mathrm{Ar}$ atmosphere. The reaction mixture was stirred at $70^{\circ} \mathrm{C}$ (oil bath temperature) under $\mathrm{Ar}$ atmosphere for $48 \mathrm{~h}$. After cooling to room temperature, $\mathrm{H}_{2} \mathrm{O}$ and $\mathrm{CHCl}_{3}$ were added, and the organic species were extracted with $\mathrm{CHCl}_{3}$. The organic layer was dried over $\mathrm{MgSO}_{4}$. After $\mathrm{MgSO}_{4}$ was removed, the solvent was evaporated. The residue was purified by high performance liquid chromatography with $\mathrm{CHCl}_{3}$ as an eluent to obtain polymer $\left(R_{\mathrm{p}}\right)-\mathrm{P} 1$ as an orange powder $(10.3 \mathrm{mg}$, $0.012 \mathrm{mmol}, 59 \%)$.

Polymer $\left(S_{\mathrm{p}}\right)$-P1 was obtained by the same procedure $(8.7 \mathrm{mg}$, $0.010 \mathrm{mmol}, 50 \%)$.

In Supplementary Information, the detailed synthetic procedures and data of compounds 3 and 4 , and the ${ }^{1} \mathrm{H}$ and ${ }^{13} \mathrm{C}$ NMR spectra of $\left(R_{\mathrm{p}}\right)$-isomers 3 (Supplementary Figures S2 and S3), 4 (Supplementary Figures S5 and S6) and P1 (Supplementary Figures S7 and S8) are shown. Chromatograms of compounds $\mathbf{3}$ and $\mathbf{4}$ with a Chiralpak IA column (Daicel Corporation, Osaka, Japan) are also shown in Supplementary Figures S1 and S4, respectively. Fluorescence decay curves with the data of polymers $\left(R_{\mathrm{p}}\right)$ - and $\left(S_{\mathrm{p}}\right)-\mathbf{P} \mathbf{1}$ are shown in Supplementary Figures S9 and S10.The optimized structure of the model compound in the excited state is shown in Supplementary Figure S11.

\section{RESULTS AND DISCUSSIONS}

The synthetic route toward the enantiopure planar chiral [2.2] paracyclophane monomer is shown in Scheme 1, in which reactions of only $\left(R_{\mathrm{p}}\right)$-isomers are shown. $\left(R_{\mathrm{p}}\right)$-4,12-Diiodo[2.2]paracyclophane, ${ }^{7,11}\left(R_{\mathrm{p}}\right)-2$, was prepared from the corresponding $\left(R_{\mathrm{p}}, S\right)$ isomer, $\left(R_{\mathrm{p}}, S\right)-\mathbf{1},{ }^{6}$ by lithiation and successive iodination. However, when a Suzuki-Miyaura cross-coupling ${ }^{12}$ polymerization of $\left(R_{\mathrm{p}}\right)-2$ with bithiophene monomer $\mathbf{5}$ was carried out, the molecular weight of the obtained polymer was quite low. Therefore, thiophene-substituted [2.2] paracyclophane was synthesized and used as a co-monomer. As shown in Scheme 1, the Suzuki-Miyaura cross-coupling of $\left(R_{\mathrm{p}}\right)-2$ with 2-thienylboronic acid produced $\left(R_{\mathrm{p}}\right)$-4,12-di(2-thienyl)[2.2] paracyclophane $\left(R_{\mathrm{p}}\right)-3$ with a $79 \%$ isolated yield. After several attempts to obtain $\left(R_{\mathrm{p}}\right)-3$, we found that the Suzuki-Miyaura cross-coupling provided the best results, in accordance with a report by Lützen and coworkers $^{7}$ on successful Suzuki-Miyaura cross-coupling between $\mathrm{rac}^{-}$ 2 and 4-methoxyphenylboronic acid. Brominations at the fifth position of both thiophene units in $\left(R_{\mathrm{p}}\right)-3$ using $N$-bromosuccinimide was carried out to obtain the target monomer $\left(R_{\mathrm{p}}\right)-4$ with a $74 \%$ 
<smiles>O=S(=O)(O)c1c(Br)cc2c(c1Br)CCC2</smiles>
$(p$-Tol) $\left(R_{\mathrm{p}}, S\right)-1$
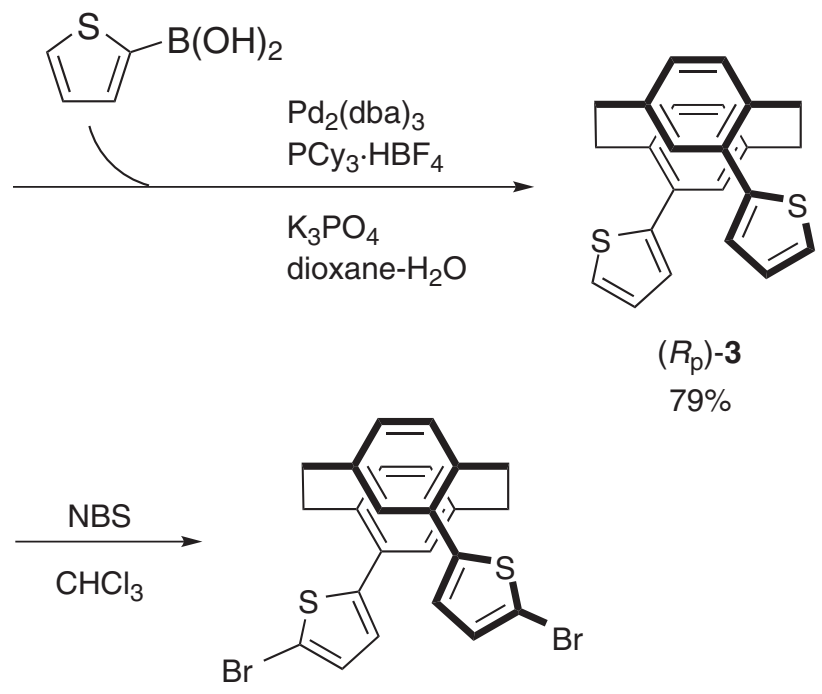

$\left(R_{\mathrm{p}}\right)-3$ $79 \%$
1) $t$-BuLi

2) $\mathrm{C}_{2} \mathrm{H}_{4} \mathrm{I}_{2}$

THF

$41 \%$

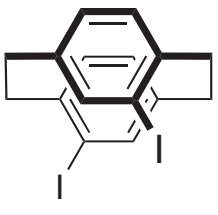

$\left(R_{\mathrm{p}}\right)-2$ 


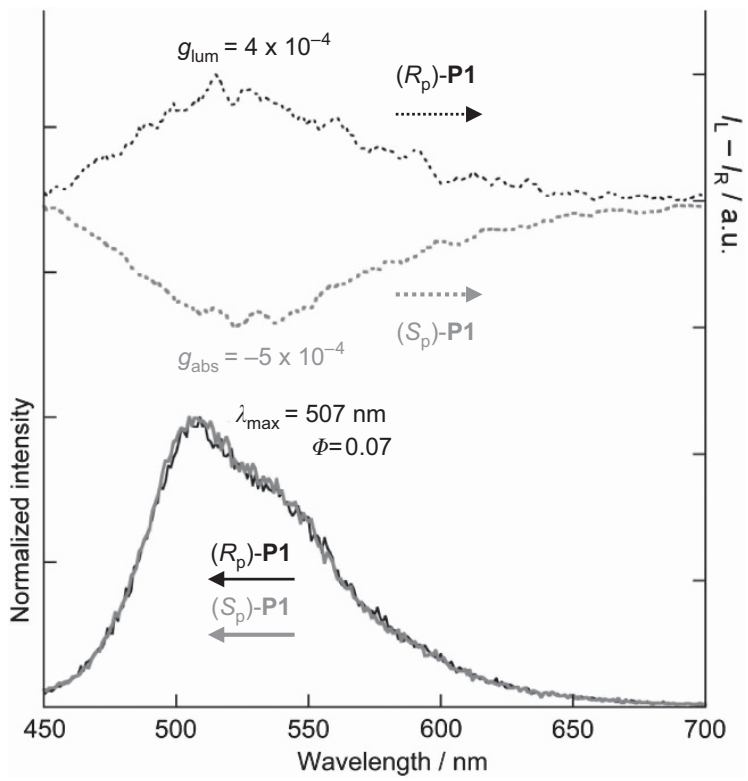

Figure 2 Photoluminescence $(\mathrm{PL})$ and circularly polarized luminescence (CPL) spectra of $\left(R_{\mathrm{p}}\right)$ - and $\left(S_{\mathrm{p}}\right)-\mathrm{P} 1$ in $\mathrm{CHCl}_{3}\left(1.0 \times 10^{-5} \mathrm{M}\right.$, excitation at $\left.380 \mathrm{~nm}\right)$. $\Phi=\mathrm{PL}$ absolute quantum efficiency (average of both $\left(R_{\mathrm{p}}\right)$ - and $\left(S_{\mathrm{p}}\right)$-isomers).
Figure 1a shows the UV-vis and CD spectra of $\left(R_{\mathrm{p}}\right)$ - and $\left(S_{\mathrm{p}}\right)-\mathbf{P 1}$ in $\mathrm{CHCl}_{3}\left(1.0 \times 10^{-5} \mathrm{M}\right)$. In the UV-vis spectra, $\left(R_{\mathrm{p}}\right)$ - and $\left(S_{\mathrm{p}}\right)-\mathrm{P} 1$ exhibited a maximum absorbance at $383 \mathrm{~nm}$. The spectra were almost identical to the spectrum of $2,2^{\prime \prime \prime}-\operatorname{di}[2.2]$ cyclophanyl $-2,2^{\prime}: 5^{\prime}, 2^{\prime \prime}$ : $5^{\prime \prime}, 2^{\prime \prime \prime}$-quaterthiophene prepared by Guyard and Audebert. ${ }^{14}$ This similarity indicates that the spectra of $\left(R_{\mathrm{p}}\right)$ - and $\left(S_{\mathrm{p}}\right)$-P1 resulted from

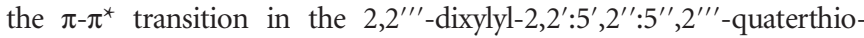
phene moiety. The CD spectra of $\left(R_{\mathrm{p}}\right)$ - and $\left(S_{\mathrm{p}}\right)-\mathbf{P} 1$ exhibited clear Cotton effects and were mirror images. In each spectrum, the CD signal was split, and the signal pattern was consistent with the predictions of the exciton chirality method ${ }^{15}$ that was based on the orientation of the two adjacent $2,2^{\prime \prime \prime}$-dixylyl-2, $2^{\prime}: 5^{\prime}, 2^{\prime \prime}: 5^{\prime \prime}, 2^{\prime \prime \prime}$-quaterthiophene chromophores (Figure $1 \mathrm{~b}$ ). The absorbance dissymmetry factors $g_{\text {abs }}$ of the peak tops are given in Figure $1\left(g_{\text {abs }}=\Delta \varepsilon / \varepsilon\right.$, where $\Delta \varepsilon$ is the difference in molar absorptivity between left and right circularly polarized light). The maximum $g_{\text {abs }}$ values of $\left(R_{\mathrm{p}}\right)-$ and $\left(S_{\mathrm{p}}\right)-\mathbf{P} 1$ at $\sim 410 \mathrm{~nm}$ were calculated to be $8 \times 10^{-4}$ and $-9 \times 10^{-4}$, respectively, which were relatively large for dilute solutions. This implies that in the dilute solution, chirality is strongly induced in stacked $2,2^{\prime \prime \prime}$-dixylyl$2,2^{\prime}: 5^{\prime}, 2^{\prime \prime}: 5^{\prime \prime}, 2^{\prime \prime \prime}$-quaterthiophenes in the ground state as a result of the planar chiral [2.2]paracyclophane skeleton.

Polymers $\left(R_{\mathrm{p}}\right)$ - and $\left(S_{\mathrm{p}}\right)$-P1 emitted green PL (Figure 2) in their $\mathrm{CHCl}_{3}$ solution $\left(1.0 \times 10^{-6} \mathrm{M}\right)$ with an absolute PL quantum efficiency

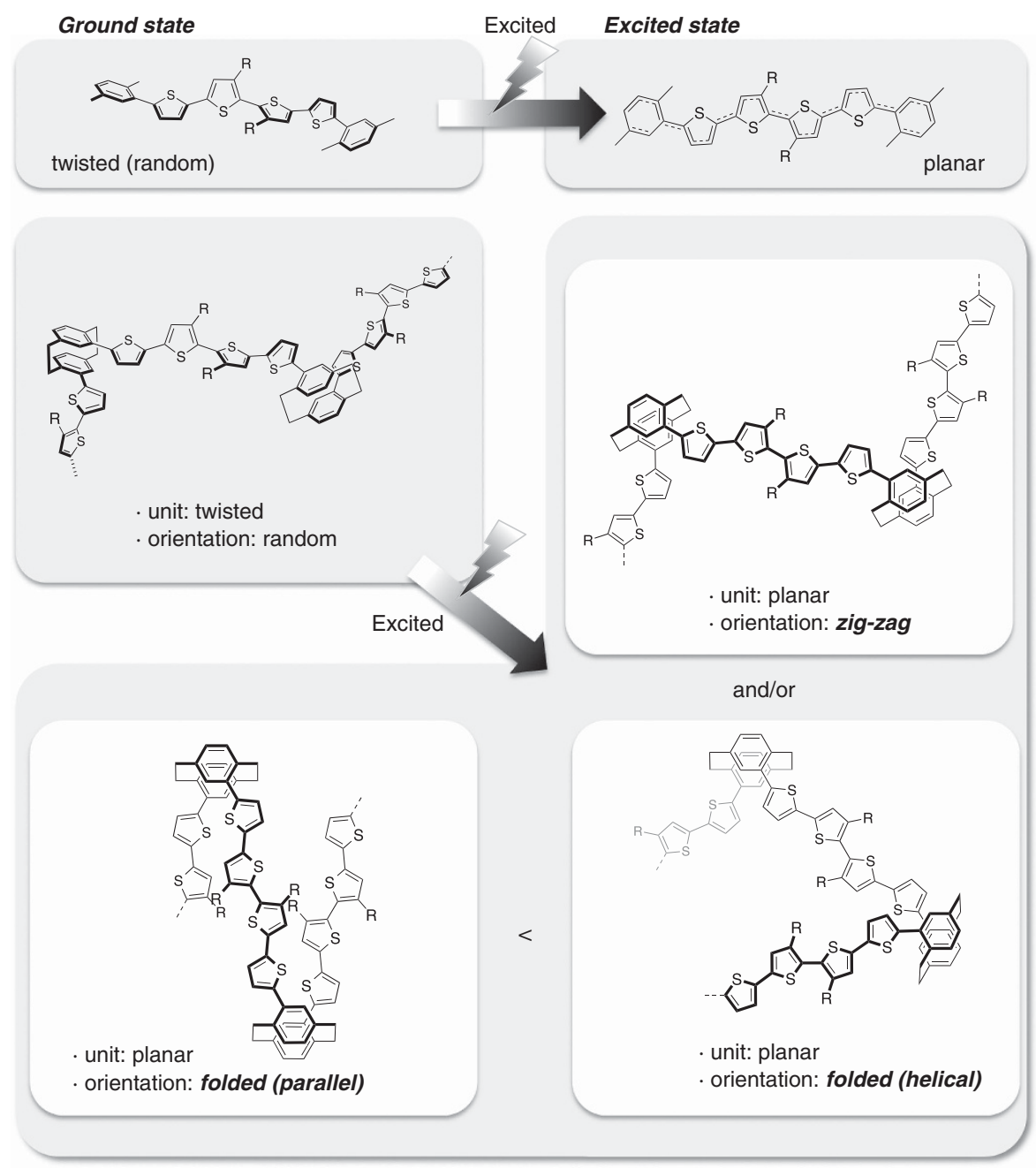

Figure 3 Plausible structures of the polymer in the ground and excited states. 
( $\left.\Phi_{\text {lum }}\right)$ of 0.07 (average value of both isomers). The emission likely arose from the chromophore state rather than the planar state, ${ }^{16}$ judging from the short PL lifetime $(\tau)$ of $0.63 \mathrm{~ns}$ (average value of both isomers) by a single exponential curve fitting (Supplementary Figures S8 and S9). Figure 2 shows the CPL spectra of $\left(R_{\mathrm{p}}\right)$ - and $\left(S_{\mathrm{p}}\right)$ P1 in $\mathrm{CHCl}_{3}$ solution $\left(1.0 \times 10^{-5} \mathrm{M}\right)$; mirror-image CPL signals were observed. The glum values of $\left(R_{\mathrm{p}}\right)$ - and $\left(S_{\mathrm{p}}\right)$-P1 were found to be $4 \times 10^{-4}$ and $-5 \times 10^{-4}$, respectively $\left(g_{\text {lum }}=2\left(I_{\mathrm{L}}-I_{\mathrm{R}}\right) /\left(I_{\mathrm{L}}+I_{\mathrm{R}}\right)\right.$, where $I_{\mathrm{L}}$ and $I_{\mathrm{R}}$ are left- and right-handed CPL signals, respectively). It is rare that a monodisperse optically active polymer in solution exhibits a clear CPL. ${ }^{13}$ Generally, CPL signals of optically active polymers appear in their films or aggregates (representative examples ${ }^{17-19}$ are listed in the reference and notes section), indicating the chiral orientation of the emitting species. In other words, a higher-ordered structure is essential for an intense CPL. The $\pi$-electron systems in the [2.2] paracyclophane-based through-space-conjugated polymer were stacked in the polymer chain, and each stacked 2,2"'-dixylyl$2,2^{\prime}: 5^{\prime}, 2^{\prime \prime}: 5^{\prime \prime}, 2^{\prime \prime \prime}$-quaterthiophene formed planar and quinoid structures in the excited state. ${ }^{20}$ Therefore, both isomers of polymer P1 should form optically active higher-ordered structures, such as zigzag, helical or parallel structures in the excited state (Figure 3). ${ }^{11}$ The PL spectrum and $\tau(0.63 \mathrm{~ns}$, single exponential decay) of $\mathbf{P} 1$ suggested an absence of intramolecular $\pi-\pi$ interactions of the $\pi$-electron systems in P1; it was unlikely to form the parallel structure (Figure 3). An optimized structure of the model oligomer comprising three stacked $\pi$-electron systems in the excited state was examined by timedependent density functional theory. The helical conformation was obtained, as shown in Supplementary Figure S11 in Supplementary Information. However, it is not the result of preventing the formation of the other structures. At present, it is difficult to conclude the conformation of the whole molecule in the excited state, such as zigzag, helical or both. In any case, it is noted that the neighboring $\pi$-electron systems in $\mathbf{P 1}$ should form the optically active, V-shaped structure by a conformationally stable planar chiral [2.2] paracyclophane. Such a chiral orientation of the emitting $\pi$-electron systems achieved in the $\mathbf{P} \mathbf{1}$ chains should result in the observed intense CPL with relatively large $g_{\text {lum }}$ values in the monodisperse state.

In conclusion, we have demonstrated the synthesis of optically active, through-space-conjugated polymers consisting of enantiopure planar chiral 4,12-disubstituted [2.2] paracyclophane and quaterthiophene. The chromatographic optical resolutions of key compounds were also achieved. The obtained optically active polymers exhibited a mirror-image Cotton effect, and the split in the CD signal was predicted by the exciton chirality method. A solution-based mirrorimage CPL response was also observed with a glum value in the order of $10^{-4}$. The next target in this research is to achieve an intense CPL with large glum values from the polymer films for practical use in CPL materials. The dibromo[2.2] paracyclophane monomer prepared in this study is highly active in Suzuki-Miyaura cross-coupling and leads to copolymerizations with various diboronic acid and ester derivatives. Additional syntheses of planar chiral [2.2] paracyclophane-based copolymers with oligothiophenes or oligofluorenes are in progress, with the goal of producing intense CPL from their films and aggregates through the formation of higher-ordered structures.

\section{ACKNOWLEDGEMENTS}

This work was supported by Grant-in-Aid for Young Scientists (A) (No. 24685018) from the MEXT. We are grateful to Professor Kazuo Akagi and Mr Kazuyoshi Watanabe (Department of Polymer Chemistry, Graduate School of Engineering, Kyoto University) for CPL data analysis.

1 Vögtle F. Cyclophane Chemistry: Synthesis, Structures and Reactions. (John Wiley \& Sons, Chichester, 1993).

2 Gleiter, R. \& Roers, R. in Modern Cyclophane Chemistry (eds Gleiter, R., Hopf H.) (Wiley-VCH, Weinheim, Germany, 2004).

3 Cram, D. J. \& Allinger, N. L. Macro rings. XII. Stereochemical consequences of steric compression in the smallest paracyclophane. J. Am. Chem. Soc. 77, 6289-6294 (1955).

4 Rowlands, G. J. The synthesis of enantiomerically pure [2.2]paracyclophane derivatives. Org. Biomol. Chem. 6, 1527-1534 (2008).

5 Pye, P. J., Rossen, K., Reamer, R. A., Tsou, N. N., Volante, R. P. \& Reider, P. J. A new planar chiral bisphosphine ligand for asymmetric catalysis: highly enantioselective hydrogenations under mild conditions. J. Am. Chem. Soc. 119, 6207-6208 (1997).

6 Morisaki, Y., Hifumi, R., Lin, L., Inoshita, K. \& Chujo, Y. Practical optical resolution of planar chiral pseudo-ortho-disubstituted [2.2]paracyclophane. Chem. Lett. 41, 990-992 (2012)

7 Meyer-Eppler, G., Vogelsang, E., Benkhäuser, C., Schneider, A., Schnakenburg, G. \& Lützen, A. Synthesis, chiral resolution, and absolute configuration of dissymmetric 4,12-difunctionalized [2.2]paracyclophanes. Eur. J. Org. Chem. 21, 4523-4532 (2013).

8 Morisaki, Y., Gon, M., Sasamori, T., Tokitoh, N. \& Chujo, Y. Planar chiral tetrasubstituted [2.2]paracyclophane: optical resolution and functionalization. J. Am. Chem. Soc. 136, 3350-3353 (2014).

9 Guyard, L. \& Audebert, P. Synthesis and electrochemical polymerization of bis-dithienyl cyclophane. Electrochem. Commun. 3, 164-167 (2001).

10 Salhi, F., Lee, B, Metz, C., Bottomley, L. A. \& Collard, D. M. Influence of $\pi$-stacking on the redox properties of oligothiophenes: ( $\alpha$-alkyloligo-thienyl)para[2.2]cyclophanes. Org. Lett. 4, 3195-3198 (2002).

11 Morisaki, Y., Inoshita, K. \& Chujo, Y. Planar chiral through-space conjugated oligomers: synthesis and characterization of chiroptical properties. Chem. Eur. J. 20, 8386-8390 (2014).

12 Miyaura, N., Yamada, K. \& Suzuki, A. A new stereospecific cross-coupling by the palladium-catalyzed reaction of 1 -alkenylboranes with 1-alkenyl or 1-alkynyl halides. Tetrahedron Lett. 20, 3437-3440 (1979).

13 Morisaki, Y., Hifumi, R., Lin, L., Inoshita, K. \& Chujo, Y. Through-space conjugated polymers consisting of planar chiral pseudo-ortho-linked [2.2]paracyclophane. Polym. Chem. 3, 2727-2730 (2012).

14 Guyard L. \& Audebert P. Synthesis and electrochemical polymerization of new oligothiophene functionalized cyclopahens. Adv. Mater. 13, 133-136 (2001)

15 Berova N. \& Nakanishi K. in Circular Dichroism: Principles and Applications (eds Nakanishi K., Berova N., Woody R.) Ch. 12, 337-382 (John Wiley \& Sons, New York, 2000).

16 Bazan, G. C. Novel organic materials through control of multichromophore interactions. J. Org. Chem. 72, 8615-8635 (2007).

17 Langeveld-Voss, B. M. W., Janssen, R. A., Christiaans, M. P. T., Meskers, S. C. J., Dekkers, H. P. J. M. \& Meijer, E. W. Circular dichroism and circular polarization of photoluminescence of highly ordered poly\{3,4-di[(S)-2-methylbutoxy]thiophene\}. J. Am. Chem. Soc. 118, 4908-4909 (1996).

18 Nakano, Y., Liu, Y. \& Fujiki, M. Ambidextrous circular dichroism and circularly polarized luminescence from poly(9,9-di-n-decylfluorene) by terpene chirality transfer. Polym. Chem. 1, 460-469 (2010).

19 Watanabe, K., Sakamoto, T., Taguchi, M., Fujiki, M. \& Nakano, T. A chiral $\pi$-stacked vinyl polymer emitting white circularly polarized light. Chem. Commun. 47, 10996-10998 (2011).

20 Chakraborty, D. \& Lagowski, J. B. Configuration interaction study of singlet excited state of thiophene and its cyano derivative oligomers. J. Chem. Phys. 115, 184-194 (2001).

Supplementary Information accompanies the paper on Polymer Journal website (http://www.nature.com/pj) 